\title{
Kinetics of murine decidual dendritic cells
}

\author{
Amir-Hassan Zarnani ${ }^{1,2,3}$, Seyed-Mohammad Moazzeni ${ }^{1}$, Fazel Shokri ${ }^{4,5}$, Mojdeh Salehnia ${ }^{6}$ and \\ Mahmood Jeddi-Tehrani ${ }^{5,7}$
}

${ }^{1}$ Department of Immunology, Faculty of Medical Sciences, Tarbiat Modarres University, Tehran, Iran, ${ }^{2}$ Department of Reproductive Immunology, Reproductive Biotechnology Research Center, Avesina Research Institute, Tehran, Iran, ${ }^{3}$ Department of Immunology, Faculty of Medicine, Iran University of Medical Sciences, Tehran, Iran, ${ }^{4}$ Department of Immunology, School of Public Health, Tehran University of Medical Sciences, Tehran, Iran, ${ }^{5}$ Monoclonal Antibody Research Center, Avesina Research Institute, Tehran, Iran, ${ }^{6}$ Department of Anatomy and Embryology, Faculty of Medical Sciences, Tarbiat Modarres University, Tehran, Iran and ${ }^{7}$ Immune and Gene Therapy Laboratory, Cancer Center Karolinska, Karolinska Hospital, Stockholm, Sweden

Correspondence should be addressed to M Jeddi-Tehrani, Monoclonal Antibody Research Center, Avesina Research Institute, PO Box 19835-177, Tehran, Iran; Email: mahjed@yahoo.com

\begin{abstract}
Dendritic cells (DCs) are professional antigen presenting cells (APC) capable of induction of primary immune responses as well as immunologic tolerance. Myeloid and lymphoid subsets of murine DCs are able to shift cytokine responses of T cells toward Th2 and Th1 profiles respectively. Thus, DCs would be suitable candidates to mediate the balance of maternal immune responses to conception. We analyzed pregnancy-related variations in uterus and splenic DCs in a murine model. C57 BL/6-mated Balb/c female mice with vaginal plugs were scarified at early, middle, and late pregnancy. Frozen sections of uterus and spleen at each stage of pregnancy were immunostained with CD11c- and MHC-II-specific antibodies. Two-color immunohistochemistry was also carried out using anti-CD11c and one of the antibodies against CD11b, CD8 $\alpha, C D 86$, and DEC-205. Using morphometric analysis, the average density of DCs and relative percentage of myeloid $\left(\mathrm{CD}_{11 c^{+}}, \mathrm{CD}_{11 \mathrm{~b}}{ }^{+}\right)$and lymphoid DCs $\left(\mathrm{CD} 11 \mathrm{c}^{+}\right.$, $\mathrm{CD8a}^{+}$) were determined at each stage. Our results showed that DCs are present throughout the pregnancy in decidua. The average density of decidual DCs at early pregnancy was significantly higher relative to middle and late gestation or to those of endometrial DCs of non-pregnant mice. Interestingly, the average density of decidual and splenic DCs, followed the same variations at different stages of pregnancy. The relative percentage of decidual lymphoid DCs (LDC) was significantly higher at mid-gestation when compared with other stages of pregnancy or non-pregnant mice. Inversely, the frequency of myeloid DCs (MDC) and the MDC/LDC ratio were statistically lower at the middle stage of pregnancy. A majority of decidual DCs expressed MHC-II and CD86. At early pregnancy, DCs were more concentrated subadjacent to the luminal epithelial layers, whereas at midor late gestation, DCs were randomly distributed in the stroma and around the epithelium. Mid-pregnancy period was a critical point with regard to splenic DCs kinetics, as both the average density of DCs and the frequency of MDCs decreased significantly when compared with early or late pregnancy, although the relative percentage of splenic LDCs did not change. Our data suggest that the balance of MDC and LDC is finely tuned throughout pregnancy, pointing an eminent immunoregulatory role of DCs in the maintenance of pregnancy.
\end{abstract}

Reproduction (2007) 133 275-283

\section{Introduction}

Dendritic cells (DCs) are the most potent antigen presenting cells (APC), which are essential for initiation of primary immune responses (Steinman 1991, Banchereau et al. 2000). These cells serve as the key regulators of immunologic mechanisms and depending on their subsets may induce immunity or immunologic tolerance. DC subsets may provide T cells with the different cytokine/molecule microenvironments that determine the classes of immune response, for example, type 1 versus type 2 CD4 helper cell profiles (Moser \& Murphy 2000). At least two distinct pathways of DC development have been identified in mice, myeloid, and lymphoid (Steinman et al. 1997, Vremec \& Shortman 1997).

Myeloid DCs (MDC) express CD11c and CD11b and induce a vigorous proliferative response in $\mathrm{CD} 4{ }^{+} \mathrm{T}$ cells, whereas lymphoid DCs (LDC) express CD11c, CD8 $\alpha$, and DEC-205 and induce a limited $\mathrm{CD} 4{ }^{+} \mathrm{T}$ cell response 
that is associated with marked T-cell apoptosis (Suss \& Shortman 1996, Vremec et al. 2000). Both subsets express high levels of class II major histocompatibility complex (MHC-II) and the co-stimulatory molecules, CD86 and CD80 (Banchereau et al. 2000).

The mechanisms leading to the fact that semiallogenic fetus is not rejected by the maternal immune system have not been completely understood and in this regard several hypotheses have been proposed. It has been postulated that during pregnancy a local phenomenon of non-specific immunosuppression might take place. Tolerance induction during pregnancy is likely to be related to the unique cocktail of hormones, cytokines, and immunoregulatory cells present at the site of blastocyst implantation (Thellin et al. 2000). There are plenty of reports indicating the presence of an immunosuppressive microenvironment at the feto-maternal interface. Fas/FasL induced apoptosis of the immune cells circulating to decidua (Hunt et al. 1997, Jerzak et al. 1998), presence of complement regulatory proteins at the feto-maternal interface (Holmes et al. 1990, 1992, Xu et al. 2000), immunoregulatory function of placental indoleamine 2,3 dioxygenase, an enzyme involved in tryptophan catabolism (Kamimura et al. 1991, Munn et al. 1998), inhibition of natural killer (NK) cellmediated cytotoxicity by human leukocyte antigen (HLA)-G and HLA-E (McMaster et al. 1995, King et al. 2000), and pivotal role of regulatory T cells in induction of maternal tolerance to paternal alloantigens (Saito et al. 2005, Zenclussen 2005) all are the immunosuppressive mechanisms which are involved in the protection of semiallogenic fetuses. Besides the immunosuppressive mechanisms mentioned above, the cytokine environment during pregnancy is also critical for successful pregnancy. According to several reports, a T-helper (Th)-2 response is necessary for a successful fetal outcome, while a Th1 response results in increased fetal loss (Lin et al. 1993, Jenkins et al. 2000, Lim et al. 2000, Piccinni et al. 2000, Croy 2001, Makhseed et al. 2001). For example, fetal loss in abortion-prone $\mathrm{CBA} / \mathrm{j} \times$ $\mathrm{DBA} / 2$ mating is due to a deficiency in the production of Th2 cytokines (Rajagopalan \& Long 1999). In humans, deviation from a Th2 cytokine response leads to spontaneous abortion as well (Hill et al. 1995, Raghupathy 2001). Although many attempts have been made to highlight the supporting role of Th2 cytokines, there are also some reports indicating that Th1 cytokines may serve a pivotal role during pregnancy (Svensson et al. 2001, Chaouat et al. 2002, 2004a, 2004b). It must be taken into consideration, however, that there are sequential windows of Th1/Th2 dominance and pregnancy is associated with very precise timing and tuning of such cytokines as, for example, Th1 cytokines exert their supporting role during early gestation period (Chaouat et al. 2002).

Regarding the importance of Th2 immunity as well as induction of tolerance to fetal allograft during pregnancy, and having considered the mutual role of DCs in induction of immunity versus tolerance and Th1 versus Th2 immune responses, it seems that these cells would be potentially suitable candidates to mediate the balance of maternal immune responses against pathogens, while retaining its capacity to support pregnancy. In fact, there is evidence that DCs could play a protective role at the human feto-maternal interface (Kammerer et al. 2000).

In our recent report, we showed variations of murine endometrial DC subsets during estrous cycle (Zarnani et al. 2006). In this study, we evaluated the frequency, localization, and immunophenotype, with emphasis on myeloid and lymphoid markers, of murine decidual DCs during early, middle, and late stages of pregnancy. In addition, to address the systemic effect of pregnancy on DC kinetics, the same variables were studied in splenic DC populations.

\section{Materials and Methods}

\section{Animals}

Female Balb/c mice (8-12 weeks) were prepared from Pasteur Institute of Iran. Mice were kept under optimal conditions of hygiene, temperature, and humidity with $12 \mathrm{~h}$ light: $12 \mathrm{~h}$ darkness cycle and were allowed food and water ad libitum. All experimental procedures on animals were approved by the ethical committee of Avesina Research Institute (ARI).

\section{Determination of gestational age}

Female Balb/c mice were allowed to mate with a male C57BL/6 and checked daily for the presence of vaginal plug. Females with vaginal plug were separated and examined for the presence of sperm in vaginal smear. The day of vaginal plug and sperm detection was considered to be the day 0.5 of pregnancy.

\section{Tissue specimens}

Non-pregnant mice and pregnant mice on gestation days (GD) 2,11 , or 18 , corresponding to early, middle, and late pregnancy periods respectively, were killed and the middle one-third of left horn of the uterus as well as spleen were removed simultaneously. Frozen sections of the tissues were cut at $5 \mu \mathrm{m}$ thickness, transferred to glass slides, air-dried at room temperature for $8 \mathrm{~h}$ and fixed in ice-cold acetone for $2 \mathrm{~min}$. The slides were then stored at $-70{ }^{\circ} \mathrm{C}$ until used.

\section{Antibodies}

The primary and secondary antibodies used in this study together with their clone, origin, isotype, and optimal working dilutions are listed in Table 1. 
Table 1 Primary and secondary antibodies used for immunohistochemical staining.

\begin{tabular}{|c|c|c|c|c|}
\hline Antigen & Clone & $\begin{array}{l}\text { Species/ } \\
\text { isotype }\end{array}$ & $\begin{array}{l}\text { Working } \\
\text { dilutions }^{\mathrm{a}}\end{array}$ & Supplier \\
\hline $\mathrm{CD} 8 \alpha$ & $83-6.7$ & Rat/lgG2a & $1: 250$ & Pharmingen \\
\hline DEC-205 & NLDC-145 & Rat/lgG2a & $1: 10$ & Serotech \\
\hline CD86 & GL1 & Rat/lgG2a & $1: 70$ & Pharmingen \\
\hline CD11b & $\mathrm{M} 1 / 70$ & Rat/lgG2b & $1: 250$ & Pharmingen \\
\hline CD11c & HL3 & $\begin{array}{l}\text { Hamster/lgG } \\
\text { group } 1\end{array}$ & $1: 70$ & Pharmingen \\
\hline I-A/I-E & $2 \mathrm{G} 9$ & Rat/lgG2a & $1: 250$ & Pharmingen \\
\hline Rat lg ${ }^{b}$ & - & $\begin{array}{l}\text { Goat } \\
\text { (multiple- } \\
\text { adsorbed) }\end{array}$ & $1: 70$ & Pharmingen \\
\hline $\begin{array}{l}\text { Hamster } \\
\operatorname{lgG}^{\mathrm{C}}\end{array}$ & $\begin{array}{l}\text { G70- } \\
\text { 204/G94-56 }\end{array}$ & $\begin{array}{l}\text { Mouse//gG1 } \\
\text { and IgG2b }\end{array}$ & $1: 250$ & Pharmingen \\
\hline
\end{tabular}

${ }^{a}$ All dilutions were made with antibody diluent (Pharmingen, Sydney, Australia). ${ }^{\mathrm{b}} \mathrm{HRP}$-conjugated. ${ }^{\mathrm{C}}$ Biotin-conjugated.

\section{Immunohistochemistry}

Acetone-fixed cryostat sections of uterus and spleen were thawed and washed thrice with $0.15 \mathrm{M}$ TBS (Tris-

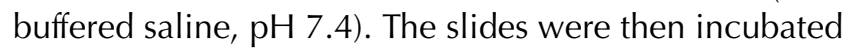
for 10 min with $5 \%$ normal mouse, goat or rat sera appropriately diluted in TBS to block non-specific bindings. For MHC-II staining, the slides were incubated with appropriate dilution of biotin-conjugated rat antimouse I-A/I-E for $1 \mathrm{~h}$. Following three washes, endogenous peroxidase activity was quenched by the addition of $0.3 \% \mathrm{H}_{2} \mathrm{O}_{2}$ in TBS. After washing with TBS, slides were incubated with horse radish peroxidase (HRP)-conjugated streptavidin (Biosource International, NY, USA) diluted in a ratio of $1: 50$ in TBS for $30 \mathrm{~min}$. Excess reagents were washed off by washing thrice with TBS followed by the addition of $\mathrm{NiSO}_{4}$-supplemented diaminobenzidine (DAB; Sigma) as substrate. Sections were counterstained with Harris hematoxylin (Sigma), dehydrated with ascending grades of ethanol each for $30 \mathrm{~s}$ and mounted in Entellan (Merck).

Staining with anti-CD11c differed from the above procedure in that the slides were stained with hamster anti-mouse CD11c, followed by incubation with biotinconjugated mouse anti-hamster IgG for $45 \mathrm{~min}$. The staining was completed as above.

For DEC-205, CD8 $\alpha$, CD11b, and CD86 staining, briefly, sections were sequentially incubated with optimally diluted primary antibodies followed by washing and addition of HRP-conjugated goat anti-rat secondary antibody. The sections were then developed and processed as above.

\section{Two-color immunohistochemistry}

Adaptation for immunohistochemical double staining was as follows: briefly, tissue sections were sequentially incubated with appropriate dilutions (Table 1) of hamster anti-mouse $\mathrm{CD} 11 \mathrm{c}$ and of rat anti-mouse DEC-205, CD8 $\alpha$, CD11b, or CD86 monoclonal antibodies for $75 \mathrm{~min}$ at room temperature followed by a mixture of HRP-conjugated goat anti-rat immunoglobulin and biotin-conjugated mouse anti-hamster IgG, and alkaline phosphatase-conjugated avidin-biotin complex (ABC; DAKO, Glostrup, Denmark). The peroxidase activity was visualized first in a controlled manner under light microscope using DAB as substrate. Following three washes with TBS, the alkaline phosphatase activity was developed by $20-30$ min incubation in the alkaline phosphatase blue substrate (Vector Laboratories, Burlingame, CA, USA). Next, the sections were rinsed in tap water, counterstained with nuclear fast red (DAKO, Glostrup, Denmark), dehydrated not more than $30 \mathrm{~s}$ in absolute ethanol, cleared with Histoclear (Vector Laboratories), and mounted with Vecta mount (Vector Laboratories). In these preparations, the alkaline phosphatase activity yielded a blue reaction product, whereas peroxidase activity appeared brown. Levamisole $(0.024 \%$; Sigma) and $\mathrm{H}_{2} \mathrm{O}_{2}(0.3 \%)$ were used to block endogenous alkaline phosphatase and peroxidase activities respectively. For co-localization of CD11c and MHC-II, serial sections of tissues were stained separately with these antibodies. In negative control slides, primary or secondary antibodies were omitted. Species-matched control sera, diluted in a ratio of 1:10, were also used, instead of primary antibodies as isotype-matched $\mathrm{Ab}$ and the results were shown to be always negative (Fig. $1 \mathrm{~d}$ and $\mathrm{h}$ ).

\section{Morphometry}

To evaluate the relative percentage of DCs expressing one of the markers of interest (CD8 $\alpha$, DEC-205, CD11b, and CD86), double positive cells were counted at $400 \times$ magnification in 40 individual fields of $0.0625 \mathrm{~mm}^{2}$ (totally $2.5 \mathrm{~mm}^{2}$ ) for each section and expressed as a percentage of the total number of $\mathrm{CD}_{11 \mathrm{C}^{+}}$cells. In single-color immunostainings for $\mathrm{CD} 11 \mathrm{c}$, positive cells were also counted in the same manner and expressed as a percentage of the total number of nucleated cells.

\section{Statistical analysis}

Five animals were used in each experimental group. Comparisons were made by non-parametric KruskalWallis test. Correlation analysis was performed using Pearson's test. $P<0.05$ was considered statistically significant.

\section{Results}

\section{Distribution of MDC and LDC in spleen and decidua}

To identify distribution and localization of MDCs and LDCs in spleen and decidua of pregnant mice, a total number of five animals were used in each experimental group. Tissue sections were stained for expression of 


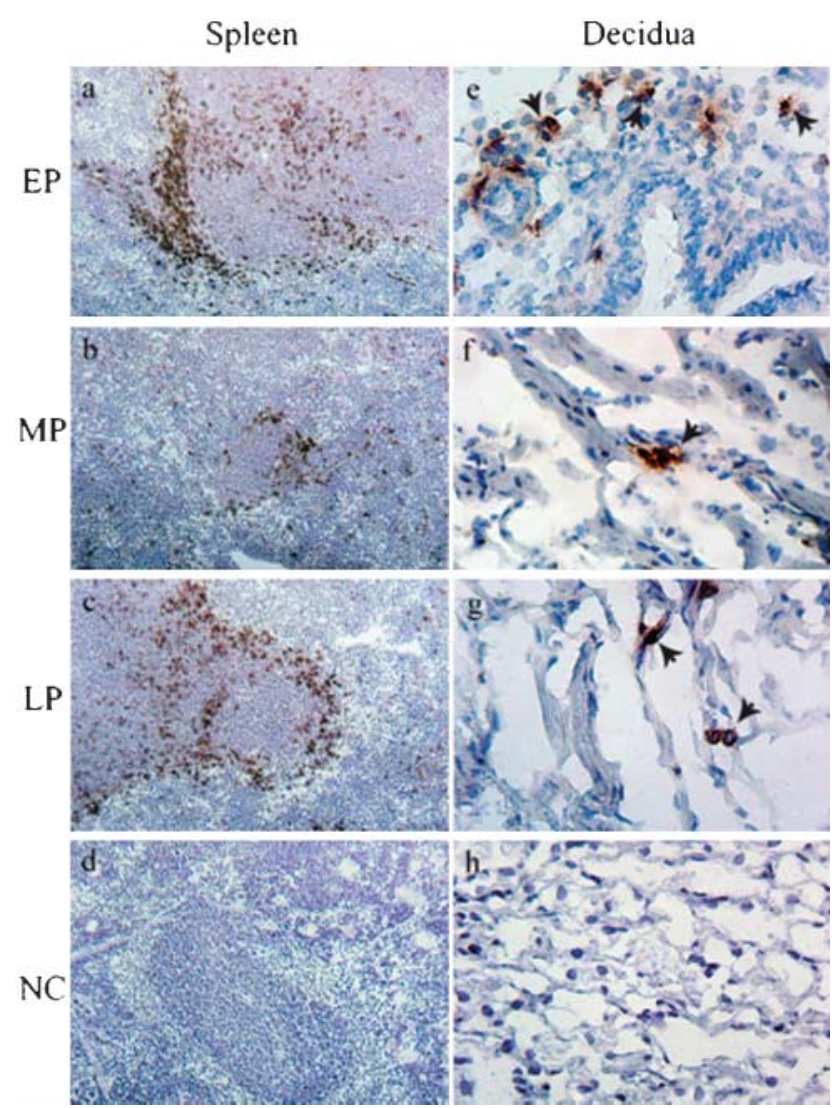

Figure 1 Immunostaining of dendritic cells in spleen and decidua of pregnant Balb/c mice. Cryosections were prepared from spleen (a-d) and uterus (e-h) of female mice and stained with CD11c. $d$ and h are negative control slides in which primary antibody was substituted by species-matched control sera. (a-d, 100×; e-h, 200×). Black arrows show decidual dendritic cells. NC, negative control; EP, early pregnancy; MP, mid-pregnancy; LP, late pregnancy.

CD11c, MHC-II, CD8 $\alpha$, DEC- 205, CD11b, and CD86 at each stage of pregnancy.

\section{Dendritic cells in spleen of pregnant mice}

DCs were present throughout the gestation in spleen of pregnant mice (Fig. 1a-c), but their percentage was highest at early pregnancy and lowest at mid-gestation $(P<0.01$; Fig. 2a). DCs were heavily distributed around the lymphoid follicles of the white pulps with some scattered in the red pulp (Fig. 1a). The average density of splenic DCs at early, middle, and late pregnancy was $1.63 \pm 0.14,0.93 \pm 0.17$, and $1.35 \pm 0.1 \%$ respectively (Fig. 2a). In all stages studied, no statistical difference was found in relative percentage of lymphoid $\left(\mathrm{CD} 11 \mathrm{c}^{+}\right.$ $\mathrm{CD} 8 \alpha^{+}$) DCs, although the relative percentage of MDCs was significantly lower at mid-gestation when compared with early or late pregnancy $(P<0.05$; Fig. $2 \mathrm{c})$. On an average, $65.2 \pm 3.4,70.2 \pm 3.5$, and $64.2 \pm 3.3 \%$ of splenic DCs expressed CD8 $\alpha$ at early, middle, and late pregnancy respectively, while the relative percentage of $\mathrm{CD}_{11 b^{+}}$DCs at the above stages was $36.5 \pm 4.7$,
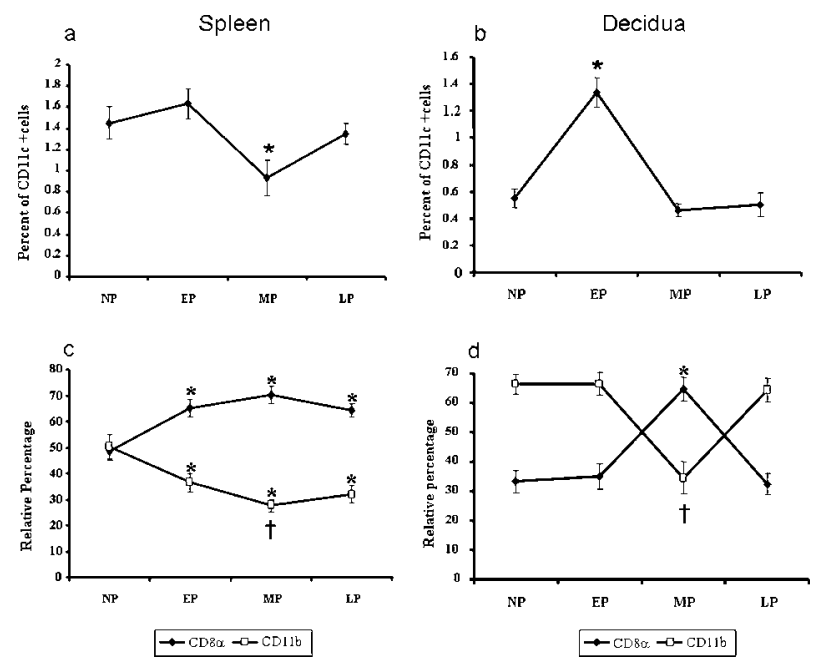

Figure 2 Comparative analysis of DCs $\left(\mathrm{CD} 11 \mathrm{c}^{+}\right), \mathrm{LDCs}\left(\mathrm{CD} 11 \mathrm{c}^{+}\right.$ $\left.\mathrm{CD} 8 \alpha^{+}\right)$, and MDCs $\left(\mathrm{CD} 11 \mathrm{c}^{+} \mathrm{CD} 11 \mathrm{~b}^{+}\right)$in spleen and decidua of pregnant Balb/c mice. Non-pregnant mice served as controls. Cryosections were prepared from spleen and uterus of female mice and stained with CD11c (a and b). Positive cells were counted and expressed as a percentage of the total number of nucleated cells. (a) Frequency of splenic DCs declined to its lowest level during midpregnancy when compared with early and late pregnancy periods or non-pregnant mice $(* P<0.01)$. (b) At early pregnancy, frequency of decidual DCs was highest relative to other stages or non-pregnant mice $\left({ }^{*} P<0.01\right)$. For immunophenotyping, double color immunohistochemistry staining was carried out using CD11c and one of the CD8 $\alpha$ or CD11b antibodies. Double positive cells were counted and expressed as a percentage of the total number of CD11 $\mathrm{c}^{+}$cells. (c) At all periods of pregnancy, relative percentage of splenic LDCs was significantly increased, while those of MDCs decreased when compared with non-pregnant mice $\left({ }^{*} P<0.05\right)$. Also, the relative percentage of myeloid DCs was significantly lower at mid-gestation when compared with early or late pregnancy $\left({ }^{\dagger} P<0.05\right.$ ). (d) The middle stage of pregnancy was a critical point in that relative percentages of decidual LDCs and MDCs were reversed when compared with other stages of pregnancy $\left(^{*,+} P<0.01\right)$. NP, non-pregnant; EP, early pregnancy; MP, mid-pregnancy; LP, late pregnancy.

$27.6 \pm 3.6$, and $31.9 \pm 2.4 \%$. At all periods of pregnancy, the relative percentage of splenic LDCs was significantly increased, while those of MDCs decreased when compared with non-pregnant mice ( $P<0.05$; Fig. 2C).

Our results also showed that the ratio of LDC/MDC at mid-gestation in spleens of pregnant mice was significantly higher than those of other stages $(P<0.05$; data not shown). In addition, we found that the majority of the splenic DCs express MHC-II $(97.9 \pm 1.8)$ and CD86 $(91.5 \pm 5.5)$ (Table 2). The expression of DEC-205 on DCs correlated strictly with that of CD $8 \alpha(r=0.87$; Fig. 3). No differences were found between different stages of pregnancy with regard to expression of CD86 and MHC-II on splenic DCs.

\section{Dendritic cells in decidua of pregnant mice:}

DCs were present in decidua at all stages of pregnancy (Fig. 1e-g). The comparative analysis of decidual DCs 
Table 2 Expression of MHC-II and CD86 on splenic and decidual CD11 ${ }^{+}$dendritic cells during different periods of pregnancy.

\begin{tabular}{|c|c|c|c|c|c|c|c|c|}
\hline & \multicolumn{4}{|c|}{ Spleen } & \multicolumn{4}{|c|}{ Decidua } \\
\hline & NP & $\mathrm{EP}$ & MP & LP & NP & EP & MP & LP \\
\hline MHC-II & $97.3 \pm 2.2$ & $98.2 \pm 1.7$ & $98 \pm 1.9$ & $97 \pm 1.6$ & $98 \pm 1.5$ & $98.6 \pm 1.4$ & $99 \pm 0.6$ & $97.8 \pm 1.9$ \\
\hline CD86 & $85.3 \pm 6.2$ & $92.3 \pm 4.8$ & $88 \pm 5.1$ & $94.2 \pm 6.7$ & $87.9 \pm 5.4$ & $91 \pm 2.8$ & $93 \pm 4.7$ & $95.1 \pm 5.6$ \\
\hline
\end{tabular}

$\mathrm{NP}$, non-pregnant; EP, early pregnancy; MP, mid-pregnancy; LP, late pregnancy. Non-pregnant mice served as control.

among three stages of pregnancy and non-pregnant mice showed that the average density of decidual DCs was significantly higher at early pregnancy $(P<0.01$; Fig. $2 b)$. The average density of DCs was $1.34 \pm 0.11,0.46 \pm 0.05$, and $0.5 \pm 0.09 \%$ at early, middle, and late pregnancy respectively. Interestingly, the average densities of splenic and decidual DCs followed similar variations at different stages of pregnancy. We examined the distribution of decidual DCs at various stages of pregnancy. DCs were present at all areas of uterus, including myometrium, mesometrium, stroma, and subepithelial layers. At early pregnancy, there were numerous DCs in decidua concentrated subadjacent to the luminal epithelial layers (Fig. 1e), whereas at middle or late pregnancy DCs were randomly distributed in stroma and around the glandular and luminal epithelial layers.

The relative percentage of LDCs was significantly higher at mid-gestation when compared with early or late pregnancy and non-pregnant mice $(P<0.01$; Fig. 2d). We found that $35.1 \pm 4.3,64.6 \pm 4$, and $32.3 \pm 3.6 \%$ of decidual DCs expressed CD $8 \alpha$ at early, middle, and late pregnancy respectively. Inversely, the relative percentage of decidual MDCs at middle pregnancy was significantly lower in comparison with other stages of pregnancy or non-pregnant mice $(P<0.01$; Fig. $2 d)$. The relative percentage of MDC at early, middle, and late pregnancy was $64.6 \pm 3.9,34.4 \pm$ 5.5 , and $64.3 \pm 4 \%$ respectively.

As expected, the LDC/MDC ratio was higher at midgestation when compared with other stages $(P<0.01$; data not shown). There was no statistical difference, with regard to MHC-II or CD86 expression on decidual DCs (Table 2), between various stages of pregnancy and the majority of decidual DCs expressed these two markers. Immunostaining with DEC-205 showed that as for $\mathrm{CD} 8 \alpha, \mathrm{DEC}-205^{+} \mathrm{CD} 11 \mathrm{c}^{+} \mathrm{DC}$ s were present in greater numbers at mid-gestation $(P<0.01)$.

\section{Discussion}

In this study, we examined the relative percentage, localization, and immunophenotype (with emphasis on myeloid and lymphoid markers) of decidual and splenic DCs of different stages of mouse pregnancy. Analysis of DC frequency in spleen of pregnant mice revealed that on an average, DCs comprised $1.3 \pm 0.11 \%$ of all splenic nucleated cells, which was statistically similar to what we found in non-pregnant mice $(1.45 \pm 0.15 \%$ ) (Zarnani et al. 2006). The average density of DCs was statistically lower at mid-gestation when compared with other stages of pregnancy or non-pregnant mice. We did not find any report on splenic DCs during gestation. Published data on peripheral DCs of pregnant women on different stages of pregnancy, however, showed that the number of peripheral blood DCs was significantly lower in the second trimester, when compared with the first and third trimesters of normal pregnancy (Rmochwal-Kolarz et al. 2003a, 2003b, Yoshimura et al. 2003). The reason for this phenomenon is not clarified, but Kolarz et al. (Rmochwal-Kolarz et al. 2003b) proposed that lower frequency of blood DCs at mid-gestation is due to their migration into the uterus. Our findings revealed that, in parallel to splenic DCs, the frequency of decidual DCs was also decreased at mid-gestation and therefore it does not seem that such migration is responsible for this phenomenon. It is possible that DCs are hormonally controlled during normal pregnancy. In rats, progesterone concentration reaches the highest level at mid-gestation (Varga et al. 1981) and a decrease in DC frequency during this period may be associated with the change in progesterone concentration.

Having considered that the relative frequency of splenic LDCs increased (although this was not statistically significant), while those of MDCs decreased significantly at mid-gestation, it seems that reduction in splenic DC frequency during this period is mainly due to a decrease in MDC populations.

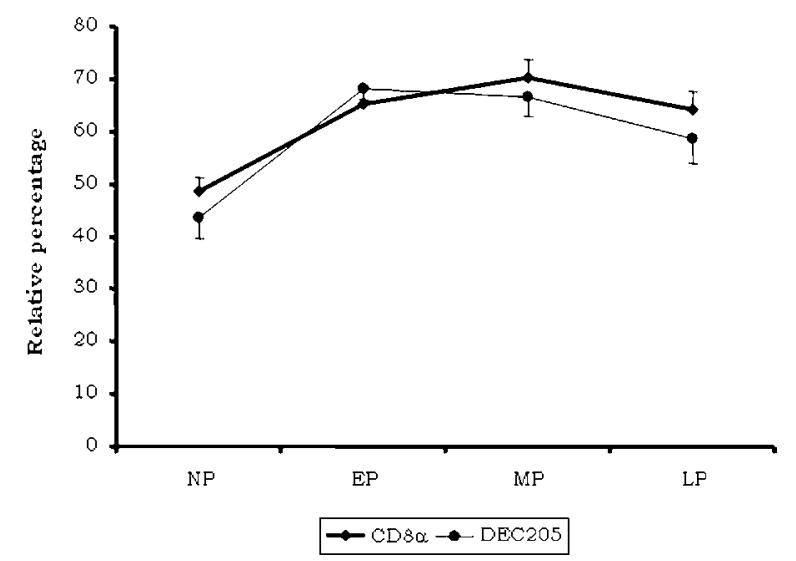

Figure 3 Expression of DEC-205 and CD8 $\alpha$ on splenic $\mathrm{CD} 11 \mathrm{c}^{+}$ dendritic cells during different periods of pregnancy. Non-pregnant mice served as controls. As shown, there is considerable correlation between the expressions of these markers on dendritic cells. NP, nonpregnant; EP, early pregnancy; MP, mid-pregnancy; LP, late pregnancy. 
It has recently been reported that the percentage of LDCs and the LDC/MDC ratio were significantly lower in the second trimester, when compared with the first or third trimesters of normal human pregnancy (Rmochwal-Kolarz et al. 2003b, Yoshimura et al. 2003). This discrepancy can be explained by considering the opposite functions of DC subsets, in human and in mice. In human, myeloid and lymphoid DCs promote Th1 and Th2 immunities respectively, while in mice, MDCs are proved to induce a Th2-biased response and LDCs have the ability to induce a Th1-biased cytokine response (Banchereau et al. 2000, Moser \& Murphy 2000). Furthermore, in contrast to non-pregnant mice in which splenic myeloid and lymphoid DCs were present equally (48.6 \pm 2.7 vs $50.3 \pm 3.4 \%$ ), lymphoid DCs were more prominent is spleens of pregnant mice $(66.5 \pm 3.4$ vs $32 \pm$ $3.6 \%$ ). We did not find statistical differences in MHC-II and CD86 expression on splenic or decidual DCs between various stages of pregnancy. However, regarding the fact that we did not analyze quantitative expression of these markers on DCs, the existence of such differences could not be ruled out. Kammerer et al. (2000) reported for the first time that CD83 ${ }^{+}$mature DCs were present in the human decidua (mean density $=4.97 \pm 1.88 / \mathrm{mm}^{2}$ ). They later traced first-trimester decidual DCs using antiDC-SIGN antibody and showed that the frequency of DC-SIGN ${ }^{+}$DC was $37 \pm 23 / \mathrm{mm}^{2}$, which was obviously higher than the frequently of $\mathrm{CD}^{+} 3^{+}$mature DCs (Kammerer et al. 2003). Taking all these data into account, it seems that in their first report, Kammerer et al. underestimated the frequency of decidual DCs as the majority of these cells were immature and CD83 is expressed exclusively on mature DCs. Indeed, decidua is a non-lymphoid tissue and DCs resident in such tissues are generally immature, undergoing maturation only after antigen uptake and migration to regional lymph nodes (Banchereau et al. 2000).

It was recently reported that the frequency of murine endometrial DCs was highest at estrus, a phase in estrous cycle in which mating occurs (Zarnani et al. in press). In the present study, we observed that mating was associated with further recruitment of large numbers of DCs into the early decidua. One important explanation for this phenomenon may be the uptake and processing of seminal proteins by DCs, leading to the induction of appropriate immune response to paternal antigens. It seems that DC recruitment to decidua is a feature of inflammatory responses induced by insemination. Introduction of the male ejaculate has been shown to cause immediate changes in leukocyte populations in the female reproductive tract of several species, including rodents, pigs, rabbits, and humans (Lovell \& Getty 1968, Phillips \& Mahler 1977, Pandya \& Cohen 1985, De et al. 1991, Robertson \& Sharkey 2001). Within hours of mating in mice, specific factors in seminal plasma including transforming growth factor $\beta$ (TGF- $\beta$ ) originating in the seminal vesicles, target epithelial cells lining the uterine lumen to elicit a surge in release of proinflammatory cytokines and chemokines, such as granulocytemonocyte colony stimulating factor (GM-CSF), interleukin 6 (IL-6), and tumor necrosis factor $\alpha$ (TNF- $\alpha$ ), which in turn provoke an influx and activation of macrophages, DCs, and neutrophils in a response resembling a clinical inflammatory reaction (Robertson et al. 1996a, Tremellen et al. 1998). According to Robertson et al. GM-CSF receptor is expressed on the majority of endometrial immune cells, including macrophages, DCs, and neutrophils (Robertson et al. 1992, 1996a).

Interestingly, it has been shown that intradermal injection of recombinant GM-CSF in patients with leprosy (Kaplan et al. 1992) or in mice (O'Sullivan et al. 1996) results in recruitment of langerhans cells in the skin. In mice, GM-CSF mRNA expression and protein secretion are upregulated 20-fold after insemination (Robertson et al. 1992). It is notable that GM-CSF mRNA expression remains elevated for $48 \mathrm{~h}$ and then declines as progesterone levels increase on day 3 and day 4 of pregnancy (Robertson et al. 1996a).

There is no direct evidence to show that progesterone may play a role in DC recruitment to the female reproductive tract, but it seems that this hormone may inhibit DC recruitment through downregulation of GM-CSF production. Pretreatment of ovariectomized mice with estradiol, but not progesterone, resulted in the induction of GM-CSF production and estradiol-induced increase was inhibited by the co-administration of progesterone (Robertson et al. 1996b). As pregnancy proceeds, the progesterone level increases and thus it is conceivable that the frequency of decidual DCs declines with the progression of pregnancy. This hypothesis is in line with our findings. Indeed, in rats, progesterone levels peak at mid-gestation (Varga et al. 1981) when, according to our results, the frequency of splenic or decidual DCs declines to its lowest level.

Comparing the relative frequency of decidual lymphoid and myeloid DCs, we found that except for the mid-gestation, MDCs predominate. In mice, MDCs shift $\mathrm{T}$ cell responses toward Th2 immunity and considering that the Th2 response is necessary for a successful pregnancy, our findings can be explained. Predominancy of the LDC subset (which promotes Th1 immunity) at mid-gestation, however, seems to be contrary to the established Th2 paradigm of pregnancy.

In general, LDCs induce a limited $\mathrm{CD}^{+} \mathrm{T}$ cell response that is associated with marked $\mathrm{T}$ cell apoptosis and induction of tolerance (Inaba et al. 1997, Vandenabeele \& Wu 1999, Banchereau et al. 2000). Therefore, it may be suggested that the predominancy of decidual LDCs at mid-gestation may serve as an important role in controlling destructive responses of maternal immune system against paternal antigens through induction of immunological tolerance. Our findings also propounded another explication for this phenomenon. We found that treatment of DCs with decidual supernatant obtained 
from allogenic pregnant mice at mid-gestation markedly blocked their ability to induce antigen-specific IFN $\gamma$ production by cultured lymph node cells (A H Zarnani, unpublished observations). Thus, this Th2 promoting effect of uterine microenvironment could compensate for inherent Th1-skewing capacity of LDCs. There are plenty of reports indicating that the main functional properties of DCs, i.e., antigen presentation and Th1/Th2 induction capacity, are controlled by environmental instructions (Stumbles et al. 1998, Kapsenberg et al. 1999, Liu et al. 2002, Vlad et al. 2003) and that the same subset of DCs in different tissues is capable of inducing distinct immune responses (Iwasaki \& Kelsall 1999). These explanations might be true for predominancy of LDCs in the spleens of pregnant mice.

In a recent study, Blois et al. (2004a) found lower frequency of splenic and uterine $\mathrm{CD} 11 \mathrm{c}^{+} \mathrm{DCs}$ at early pregnancy and that frequency of such cells reached its highest level at mid-gestation. In addition, in blood, the percentage of LDCs was significantly highest at midgestation, while uterine LDCs predominated at early pregnancy. What we found in the present study is in contrast to the above-mentioned findings. Although both studies have monitored phenotype and lineage of DCs in different periods of murine pregnancy, however, there are some fundamental differences. First, in their study, Blois et al. used CBA/J $\times$ DBA/2 model, which is known to be abortion prone and according to the several reports may suffer from many immunological defects leading to abortion, including imbalance of DC population, as the same group (Blois et al. 2004b) reported in their next study that therapy with DCs normalize abortion rate in this model. Indeed, in the $\mathrm{CBA} / \mathrm{J} \times \mathrm{DBA} / 2$ model, fetal resorption occurs at mid-gestation, a critical period that according to Blois et al. and also our findings during which major changes are happening, and it is interesting to note that the major differences between findings of Blois et al. and the present study are in this period. Moreover, Rmochwal-Kolarz (2003a) also reported lower frequency of peripheral blood DCs in the second trimester of normal human pregnancy supporting the data presented here. On the other hand, according to Blois et al., the percentage of the uterine $\mathrm{CD} 11 \mathrm{c}^{+}$cells at mid-gestation is about $15 \%$, which is unexpectedly high, as the frequency of these cells in such lymphoid organs as spleen, which is heavily populated by DCs is around 1.5\% (Steinman \& Cohn 1973, Zarnani et al. 2006). Second, we analyzed decidual and splenic DCs instead of looking at uterine and peripheral blood DCs, which might be different in terms of DC frequency or phenotype. Third, completely different methods (immunohistochemistry versus flow cytometry) have been used for immunophenotyping of DCs in these studies.

Differential recruitment of MDCs and LDCs to the fetomaternal interface at different stages of pregnancy is probably influenced by different arrays of chemokines produced in situ (Kayisli et al. 2002, Penna et al. 2002).
Conversely, different subsets of DCs could modulate the outgoing immune response through production of different chemokines, which are able to recruit Th1/ Th2/Treg cells (Bonecchi et al. 1998, Loetscher et al. 1998, lellem et al. 2001, Sebastiani et al. 2001).

In conclusion, we characterized distribution and immunophenotype, with emphasis on myeloid and lymphoid markers, of CD11 $\mathrm{c}^{+}$DCs in the decidua and spleen of pregnant mice during different stages of gestation. Data presented here, reveal that frequency and subset of splenic and decidual DCs are finely tuned in a timely manner throughout pregnancy. Therefore, such balance may be relevant to the immunology of successful pregnancy and shed light on the complex networks of immunoregulation at the feto-maternal interface.

\section{Acknowledgements}

This work was supported by grants from Avesina Research Institute and Tarbiat Modares University. The authors wish to thank Ali Ahmad Bayat and Ahmad Reza Mahmoodi for their technical assistance and Parvaneh Ahmadi for her assistance in preparing the manuscript. The authors declare that there is no conflict of interest that would prejudice the impartiality of this scientific work.

\section{References}

Banchereau J, Briere F, Caux C, Davoust J, Lebecque S, Liu YJ, Pulendran B \& Palucka K 2000 Immunobiology of dendritic cells. Annual Review of Immunology 18 767-811.

Blois SM, Alba Soto CD, Tometten M, Klapp BF, Margni RA \& Arck PC 2004a Lineage, maturity and phenotype of uterine dendritic cells throughout gestation indicate a protective role in maintaining pregnancy. Biology of Reproduction 70 1018-1023.

Blois SM, Alba Soto CD, Olmos S, Chuluyan E, Gentile T, Arck PC \& Margni RA 2004b Therapy with dendritic cells influences the spontaneous resorption rate in the $\mathrm{CBA} / \mathrm{J} \times \mathrm{DBA} / 2 \mathrm{~J}$ mouse model. American Journal of Reproductive Immunology 51 40-48.

Bonecchi R, Bianchi G, Bordignon PP, D'Ambrosio D, Lang R, Borsatti A, Sozzani S, Allavena P, Gray PA, Mantovani A \& Sinigaglia F 1998 Differential expression of chemokine receptors and chemotactic responsiveness of type $1 \mathrm{~T}$ helper cells (Th1s) and Th2s. Journal of Experimental Medicine 187 129-134.

Chaouat G, Zourbas S, Ostojic S, Lappree-Delage G, Dubanchet S, Ledee N \& Martal J 2002 A brief review of recent data on some cytokine expression at the materno-foetal interface which might challenge the classical Th1/Th2 dichtomy. Journal of Reproductive Immunology 53 241-256.

Chaouat G, Ledee-Bataille N, Dubanchet S, Zourbas S, Sandra O \& Martal J 2004a Reproductive immunology 2003: reassessing the Th1/Th2 paradigm? Immunology Letters 92 207-214.

Chaouat G, Ledee-Bataille N, Dubanchet S, Zourbas S, Sandra O \& Martal J 2004b Th1/Th2 paradigm in pregnancy lost?. International Archives of Allergy and Immunology 134 93-119.

Croy BA 2001 Where now for the Th1/Th2 paradigm of the gestational uterus? Journal of Reproductive Immunology 51 1-2.

De M, Choudhuri R \& Wood GW 1991 Determination of the number and distribution of macrophages, lymphocytes, and granulocytes in the mouse uterus from mating through implantation. Journal of Leukocyte Biology 50 252-262. 
Hill JA, Polgar K \& Anderson DJ 1995 T-helper 1-type immunity to trophoblast in women with recurrent spontaneous abortion. JAMA 273 1933-1936.

Holmes CH, Simpson KL, Wainwright SD, Tate CG, Houlihan JM, Sawyer IH, Rogers IP, Spring FA, Anstee DJ \& Tanner MJ 1990 Preferential expression of the complement regulatory protein decay accelerating factor at the fetomaternal interface during human pregnancy. Journal of Immunology 144 3099-3105.

Holmes WE, Sliwkowski MX, Akita RW, Henzel WJ, Lee J, Park JW, Yansura D, Abadi N, Raab H \& Lewis GD 1992 Identification of heregulin, a specific activator of p185erbB2. Science $\mathbf{2 5 6}$ 1205-1210.

Hunt JS, Vassmer D, Ferguson TA \& Miller L 1997 Fas ligand is positioned in mouse uterus and placenta to prevent trafficking of activated leukocytes between the mother and the conceptus. Journal of Immunology 158 4122-4128.

Iellem A, Mariani M, Lang R, Recalde H, Panina-Bordignon P, Sinigaglia F \& D'Ambrosio D 2001 Unique chemotactic response profile and specific expression of chemokine receptors CCR4 and CCR8 by $\mathrm{CD} 4(+) \mathrm{CD} 25(+)$ regulatory $\mathrm{T}$ cells. Journal of Experimental Medicine 194 847-853.

Inaba K, Pack M, Inaba M, Sakuta H, Isdell F \& Steinman RM 1997 High levels of a major histocompatibility complex II-self peptide complex on dendritic cells from the $\mathrm{T}$ cell areas of lymph nodes. Journal of Experimental Medicine 186 665-672.

Iwasaki A \& Kelsall BL 1999 Freshly isolated Peyer's patch, but not spleen, dendritic cells produce interleukin 10 and induce the differentiation of $\mathrm{T}$ helper type 2 cells. Journal of Experimental Medicine 190 229-239.

Jenkins C, Roberts J, Wilson R, MacLean MA, Shilito J \& Walker JJ 2000 Evidence of a $T(H) 1$ type response associated with recurrent miscarriage. Fertility and Sterility 73 1206-1208.

Jerzak M, Kasprzycka M, Wierbicki P, Kotarski J \& Gorski A 1998 Apoptosis of T cells in the first trimester human decidua. American Journal of Reproductive Immunology 40 130-135.

Kamimura S, Eguchi K, Yonezawa M \& Sekiba K 1991 Localization and developmental change of indoleamine 2,3-dioxygenase activity in the human placenta. Acta Medica Okayama 45 135-139.

Kammerer U, Schoppet M, McLellan AD, Kapp M, Huppertz HI, Kampgen E \& Dietl J 2000 Human decidua contains potent immunostimulatory CD83(+) dendritic cells. American Journal of Pathology 157 159-169.

Kammerer U, Eggert AO, Kapp M, McLellan AD, Geijtenbeek TB, Dietl J, van KY \& Kampgen E 2003 Unique appearance of proliferating antigen-presenting cells expressing DC-SIGN (CD209) in the decidua of early human pregnancy. American Journal of Pathology 162 887-896.

Kaplan G, Walsh G, Guido LS, Meyn P, Burkhardt RA, Abalos RM, Barker J, Frindt PA, Fajardo TT \& Celona R 1992 Novel responses of human skin to intradermal recombinant granulocyte/macrophagecolony-stimulating factor: Langerhans cell recruitment, keratinocyte growth, and enhanced wound healing. Journal of Experimental Medicine 175 1717-1728.

Kapsenberg ML, Hilkens CM, Wierenga EA \& Kalinski P 1999 The paradigm of type 1 and type 2 antigen-presenting cells. Implications for atopic allergy. Clinical and Experimental Allergy 29 (Supplement 2) 33-36.

Kayisli UA, Mahutte NG \& Arici A 2002 Uterine chemokines in reproductive physiology and pathology. American Journal of Reproductive Immunology 47 213-221.

King A, Allan DS, Bowen M, Powis SJ, Joseph S, Verma S, Hiby SE, McMichael AJ, Loke YW \& Braud VM 2000 HLA-E is expressed on trophoblast and interacts with CD94/NKG2 receptors on decidual NK cells. European Journal of Immunology 30 1623-1631.

Lim KJ, Odukoya OA, Ajjan RA, Li TC, Weetman AP \& Cooke ID 2000 The role of T-helper cytokines in human reproduction. Fertility and Sterility 73 136-142.
Lin H, Mosmann TR, Guilbert L, Tuntipopipat S \& Wegmann TG 1993 Synthesis of T helper 2-type cytokines at the maternal-fetal interface. Journal of Immunology 151 4562-4573.

Liu HY, Buenafe AC, Matejuk A, Ito A, Zamora A, Dwyer J, Vandenbark AA \& Offner H 2002 Estrogen inhibition of EAE involves effects on dendritic cell function. Journal of Neuroscience Research 70 238-248.

Loetscher P, Uguccioni M, Bordoli L, Baggiolini M, Moser B, Chizzolini C \& Dayer JM 1998 CCR5 is characteristic of Th1 lymphocytes. Nature 391 344-345.

Lovell JW \& Getty R 1968 Fate of semen in the uterus of the sow: histologic study of endometrium during the 27 hafter natural service. American Journal of Veterinary Research 29 609-625.

Makhseed M, Raghupathy R, Azizieh F, Omu A, Al-Shamali E \& Ashkanani L 2001 Th1 and Th2 cytokine profiles in recurrent aborters with successful pregnancy and with subsequent abortions. Human Reproduction 16 2219-2226.

McMaster MT, Librach CL, Zhou Y, Lim KH, Janatpour MJ, DeMars R, Kovats S, Damsky C \& Fisher SJ 1995 Human placental HLA-G expression is restricted to differentiated cytotrophoblasts. Journal of Immunology 154 3771-3778.

Moser M \& Murphy KM 2000 Dendritic cell regulation of TH1-TH2 development. Nature Immunology 1 199-205.

Munn DH, Zhou M, Attwood JT, Bondarev I, Conway SJ, Marshall B, Brown C \& Mellor AL 1998 Prevention of allogeneic fetal rejection by tryptophan catabolism. Science 281 1191-1193.

O'Sullivan GM, Sluyter R, Boswell CM, Barnetson RS \& Halliday GM 1996 Modulation of la + Langerhans cell numbers in vivo by cultured epidermis derived supernatants and by GM-CSF. Experimental Dermatology 5 28-37.

Pandya IJ \& Cohen J 1985 The leukocytic reaction of the human uterine cervix to spermatozoa. Fertility and Sterility 43 417-421.

Penna G, Vulcano M, Sozzani S \& Adorini L 2002 Differential migration behavior and chemokine production by myeloid and plasmacytoid dendritic cells. Human Immunology 63 1164-1171.

Phillips DM \& Mahler S 1977 Leukocyte emigration and migration in the vagina following mating in the rabbit. Anatomical Record 189 45-59.

Piccinni MP, Scaletti C, Maggi E \& Romagnani S 2000 Role of hormone-controlled Th1- and Th2-type cytokines in successful pregnancy. Journal of Neuroimmunology 109 30-33.

Raghupathy R 2001 Pregnancy: success and failure within the Th1/Th2/Th3 paradigm. Seminars in Immunology 13 219-227.

Rajagopalan S \& Long EO 1999 A human histocompatibility leukocyte antigen (HLA)-G-specific receptor expressed on all natural killer cells. Journal of Experimental Medicine 189 1093-1100.

Rmochwal-Kolarz D, Rolinski J, Tabarkiewicz J, LeszczynskaGorzelak B, Buczkowski J, Wojas K \& Oleszczuk J 2003a Myeloid and lymphoid dendritic cells in normal pregnancy and pre-eclampsia. Clinical and Experimental Immunology 132 339-344.

Rmochwal-Kolarz D, Rolinski J, Tabarkiewicz J, LeszczynskaGorzelak B, Buczkowski J, Wojas K \& Oleszczuk J 2003b Blood myeloid and lymphoid dendritic cells are stable during the menstrual cycle but deficient during mid-gestation. Journal of Reproductive Immunology 59 193-203.

Robertson SA \& Sharkey DJ 2001 The role of semen in induction of maternal immune tolerance to pregnancy. Seminars in Immunology 13 243-254.

Robertson SA, Mayrhofer G \& Seamark RF 1992 Uterine epithelial cells synthesize granulocyte-macrophage colony-stimulating factor and interleukin-6 in pregnant and nonpregnant mice. Biology of Reproduction 46 1069-1079.

Robertson SA, Mau VJ, Tremellen KP \& Seamark RF 1996a Role of high molecular weight seminal vesicle proteins in eliciting the uterine inflammatory response to semen in mice. Journal of Reproduction \& Fertility 107 265-277. 
Robertson SA, Mayrhofer G \& Seamark RF $1996 b$ Ovarian steroid hormones regulate granulocyte-macrophage colony-stimulating factor synthesis by uterine epithelial cells in the mouse. Biology of Reproduction 54 183-196.

Saito S, Sasaki Y \& Sakai M 2005 CD4(+)CD25high regulatory T cells in human pregnancy. Journal of Reproductive Immunology 65 111-120.

Sebastiani S, Allavena P, Albanesi C, Nasorri F, Bianchi G, Traidl C, Sozzani S, Girolomoni G \& Cavani A 2001 Chemokine receptor expression and function in $\mathrm{CD} 4+\mathrm{T}$ lymphocytes with regulatory activity. Journal of Immunology 166 996-1002.

Steinman RM 1991 The dendritic cell system and its role in immunogenicity. Annual Review of Immunology 9 271-296.

Steinman RM \& Cohn ZA 1973 Identification of a novel cell type in peripheral lymphoid organs of mice I. Morphology, quantitation, tissue distribution. Journal of Experimental Medicine 137 1142-1162.

Steinman RM, Pack M \& Inaba K 1997 Dendritic cells in the T-cell areas of lymphoid organs. Immunological Reviews 156 25-37.

Stumbles PA, Thomas JA, Pimm CL, Lee PT, Venaille TJ, Proksch S \& Holt PG 1998 Resting respiratory tract dendritic cells preferentially stimulate Thelper cell type 2 (Th2) responses and require obligatory cytokine signals for induction of Th1 immunity. Journal of Experimental Medicine 188 2019-2031.

Suss G \& Shortman K 1996 A subclass of dendritic cells kills CD4 T cells via Fas/Fas-ligand-induced apoptosis. Journal of Experimental Medicine 183 1789-1796.

Svensson L, Arvola M, Sallstrom MA, Holmdahl R \& Mattsson R 2001 The Th2 cytokines II-4 and II-10 are not required for the completion of allogenic pregnancy in mice. Journal of Reproductive Immunology 51 3-7.

Thellin O, Coumans B, Zorzi W, Igout A \& Heinen E 2000 Tolerance to the foeto-placental 'graft': ten ways to support a child for nine months. Current Opinion in Immunology 12 731-737.

Tremellen KP, Seamark RF \& Robertson SA 1998 Seminal transforming growth factor beta1 stimulates granulocyte-macrophage colonystimulating factor production and inflammatory cell recruitment in the murine uterus. Biology of Reproduction 58 1217-1225.
Vandenabeele S \& Wu L 1999 Dendritic cell origins: puzzles and paradoxes. Immunology and Cell Biology 77 411-419.

Varga B, Patay ES, Horvath E \& Folly G 1981 Ovarian venous outflow, progesterone and 17 beta-oestradiol secretion and peripheral blood level during pregnancy in the rat. Acta Physiologica Academiae Scientiarum Hungaricae 58 141-146.

Vlad G, Piazza F, Colovai A, Cortesini R, Della PF, Suciu-Foca N \& Manavalan JS 2003 Interleukin-10 induces the upregulation of the inhibitory receptor ILT4 in monocytes from HIV positive individuals. Human Immunology 64 483-489.

Vremec D \& Shortman K 1997 Dendritic cell subtypes in mouse lymphoid organs: cross-correlation of surface markers, changes with incubation, and differences among thymus, spleen, and lymph nodes. Journal of Immunology 159 565-573.

Vremec D, Pooley J, Hochrein H, Wu L \& Shortman K 2000 CD4 and CD8 expression by dendritic cell subtypes in mouse thymus and spleen. Journal of Immunology 164 2978-2986.

Xu C, Mao D, Holers VM, Palanca B, Cheng AM \& Molina H 2000 A critical role for murine complement regulator crry in fetomaternal tolerance. Science $\mathbf{2 8 7}$ 498-501.

Yoshimura T, Inaba M, Sugiura K, Nakajima T, Ito T, Nakamura K, Kanzaki H \& Ikehara S 2003 Analyses of dendritic cell subsets in pregnancy. American Journal of Reproductive Immunology $\mathbf{5 0}$ 137-145.

Zarnani AH, Moazzeni SM, Shokri F, Salehnia M \& Jeddi Tehrani M 2006 Analysis of endometrial myeloid and lymphoid dendritic cells during mouse estrous cycle. Journal of Reproductive Immunology $\mathbf{7 1}$ 28-40.

Zenclussen AC 2005 CD4(+)CD25+T regulatory cells in murine pregnancy. Journal of Reproductive Immunology 65 101-110.

Received 20 April 2006

First decision 20 June 2006

Revised manuscript received 15 August 2006

Accepted 25 October 2006 